\title{
A crosscorrelation methodology for in vivo pharmacokinetic study by the trans-scale fluorescent system
}

Yueqing Gu ( $\sim$ guengineering@cpu.edu.cn )

China Pharmaceutical University

Siwen Li ( $\nabla$ lsw@cpu.edu.cn )

China Pharmaceutical University

Qiao Lin

Yi Ma

Lu Qian

Lijun Wang

Xin Wang

Feilong Wang

Yixin Zhao

Hua He

Fang Zhou

Ying Peng

Liwei Liu

Junle Qu

Zhaohui Wang

\section{Method Article}

Keywords:

Posted Date: January 17th, 2022

DOI: https://doi.org/10.21203/rs.3.pex-1733/v2

License: (a) (i) This work is licensed under a Creative Commons Attribution 4.0 International License.

Read Full License 


\section{Abstract}

The authors have withdrawn this protocol as it was submitted to Protocol Exchange by mistake. 